\title{
Effect of Cardiac Resynchronization Therapy on Endothelium-Dependent Vasodilatation in the Cutaneous Microvasculature
}

\author{
Erik Tesselaar, Angelique Schiffer, Jos Widdershoven, Herman Broers, \\ Eric Hendriks, Kees Luijten and John Creusen
}

\section{Linköping University Post Print}

N.B.: When citing this work, cite the original article.

This is the authors' version of the following article:

Erik Tesselaar, Angelique Schiffer, Jos Widdershoven, Herman Broers, Eric Hendriks, Kees Luijten and John Creusen, Effect of Cardiac Resynchronization Therapy on EndotheliumDependent Vasodilatation in the Cutaneous Microvasculature, 2012, Pacing and Clinical Electrophysiology, (35), 4, 377-384.

which has been published in final form at:

http://dx.doi.org/10.1111/j.1540-8159.2011.03313.x

Copyright: Wiley-Blackwell

http://eu.wiley.com/WileyCDA/Brand/id-35.html

Postprint available at: Linköping University Electronic Press

http://urn.kb.se/resolve?urn=urn:nbn:se:liu:diva-77334 
Effect of cardiac resynchronization therapy on endothelium-dependent vasodilatation in the cutaneous microvasculature

Erik (E.J.) Tesselaar, Ph.D. ${ }^{1,4}$, Angélique (A.A.J.J.) Schiffer, Ph.D. ${ }^{3}$, Jos (J.W.M.G)

5 Widdershoven, Ph.D., M.D. ${ }^{2}, H_{e r m a n}(H$.$) Broers ^{2}$,Eric (E.) Hendriks ${ }^{2}$, Kees (C.) Luijten ${ }^{2}$, John (J.H.) Creusen ${ }^{1}$

${ }^{1}$ Department of Clinical Physics, ${ }^{2}$ Department of Cardiology, ${ }^{3}$ Department of Medical Psychology, TweeSteden Ziekenhuis, Tilburg, The Netherlands

${ }^{4}$ Department of Clinical and Experimental Medicine, Faculty of Health Sciences, University

10 Hospital, Linköping, Sweden

\section{Running title}

CRT and endothelial function

\section{Correspondence}

15 Erik Tesselaar, Ph.D., Department of Clinical and Experimental Medicine, University Hospital of Linköping, SE-581 85 Linköping, Sweden, Phone: + 4610103 37 56, Fax: + 46 1010328 36, E-mail: erik.tesselaar@liu.se

\section{Funding}

This work was supported by Medtronic NL B.V., Heerlen, The Netherlands and by the

20 Center of Research on Psychology in Somatic Diseases (CoRPS), Department of Medical Psychology, Tilburg University, the Netherlands.

\section{Conflict of Interest}

This work was financially supported by Medtronic NL B.V., Heerlen, The Netherlands. 


\section{Abstract}

$25 \quad$ Aims

Cardiac resynchronization therapy (CRT) improves hemodynamic parameters, exercise capacity, symptoms, functional status and prognosis among patients with chronic heart failure (CHF). The role of the vascular endothelium in these improvements is largely unknown. In this study, we aimed to investigate whether the endothelium-dependent reactivity of the peripheral microcirculation improves in CHF patients during the first 2

30 months of CRT.

Methods We used local heating and iontophoresis of acetylcholine (ACh) and sodium nitroprusside (SNP) to measure endothelial function and smooth muscle function in the cutaneous microvasculature of $11 \mathrm{CHF}$ patients before and 2 months after CRT.

Results We found that the perfusion response in the skin to local heating was

35 increased 2 months post-CRT compared with baseline, both in terms of maximum perfusion (baseline: 113 [90-137]versus. 2-months post-CRT: 137 [98-175], $\mathrm{p}=0.037$ ) and area under curve (baseline: 1601 [935 to 2268] versus 2-months CRT: 2205 [1654 to 2757], p = 0.047). Also, the perfusion response to iontophoresis of ACh was improved ( $E_{\max }: 23.9$ [20.6 to 26.2] vs at 2-months CRT: 31.2 [29.3 to 33.4], $\mathrm{p}=0.005$ ). No difference was found between the

40 responses to SNP before and after CRT.

Conclusion These results show that CRT improves endothelium-dependent vasodilatory capacity in the peripheral microcirculation within 2 months of therapy. The improvement in functional capacity that is seen in patients treated with CRT may therefore be in part mediated by an improvement of endothelium-dependent vasodilatory capacity.

45 Key words: heart failure, biventricular pacing, endothelium, microcirculation 


\section{Introduction}

In chronic heart failure (CHF) patients, the function of major and intermediate vessels in the systemic circulation and microvascular function are compromised $(2 ; 3)$. In recent years, the role of a failing endothelium in CHF has been recognised and investigated (4;5). Both myocardial and peripheral perfusion are impaired, partly due to a reduction in endotheliumdependent vasodilatory capacity. It has been suggested that the severity of endothelial dysfunction can be used as a prognostic factor for the long term outcome in CHF and coronary artery disease $(5 ; 6)$. Andreassen and colleagues $(7)$ found that peripheral endothelial -dependent vasodilatation is attenuated in candidates for heart transplantation, but improves within the first year after the transplantation (8). Also, peripheral endothelial function one month after the transplantation may be used to identify the risk of cardiac allograft vasculopathy (9).

In a subgroup of $\mathrm{CHF}$ patients, cardiac output is reduced due to asynchronous contraction of the ventricles. These patients can be treated with cardiac synchronisation therapy (CRT) by

60 implanting a biventricular pacemaker. In large-scale clinical trials, CRT has been shown to improve haemodynamic parameters, exercise capacity, symptoms, and functional status, and to reduce mortality and hospitalisation (10-12). However, the mechanisms responsible for these improvements are not yet understood.

A recent study by Akar and colleagues (13) indicated that a dysfunctioning endothelium might identify responders to CRT (as defined using the Clinical Composite Score), but they were not able to find a significant improvement in endothelial function in these responders. In another study it is shown that biventricular pacing leads to an acute improvement in microvascular perfusion (14), but it is unknown whether CRT restores the impaired endothelium-dependent vasodilatory capacity on the longer term. 
70 We hypothesised that the improvement in functional capacity that is seen in CHF patients treated with CRT may be mediated by an improvement of endothelial function. The aim of this study was therefore to investigate whether the endothelium-dependent reactivity of the peripheral microcirculation improves in CHF patients during the first 2 months of CRT.

\section{Methods}

\section{Study Population}

Between April 2008 and November 2009, all CHF patients eligible for CRT at the Cardiology Department of the TweeSteden teaching Hospital in Tilburg, the Netherlands, were approached for participation in the current study. Twelve patients were asked for participation and $11(92 \%)$ agreed and completed the baseline assessment and follow-up after

802 months ( 5 women, mean age $70.5 \pm 7.4$ years, range 62 to 83 years).

All patients were treated according to the most recent ACC/AHA guidelines $(15 ; 16)$. They all had symptomatic CHF (New York Heart Association (NYHA) classes III or IV), delayed ventricular conduction (QRS duration $195 \pm 5 \mathrm{~ms}$ ), and were on optimal medical therapy. Nine patients were implanted with a biventricular pacemaker, 2 with a biventricular pacemaker/defibrillator. Inclusion criteria for CRT, and thereby for this study, were (1) diagnosis of systolic CHF, (2) being on optimal medical therapy, (3) NYHA functional class III or IV, with a QRS duration $\geq 120 \mathrm{~ms}$, and (4) left ventricular ejection fraction (LVEF) $\leq 40 \%$. In addition, (5) at least one of the following echocardiographic criteria had to be fulfilled: an aortic pre-ejection delay $>140 \mathrm{~ms}$, an interventricular mechanical delay $>40 \mathrm{~ms}$, or delayed activation of the posterolateral left ventricular wall. Patients were asked to refrain from ingesting alcohol, caffeine and vitamin $\mathrm{C}$ for 6 hours before the start of the measurements. Also, they were asked not to take any vasoactive medication in the morning prior to the measurement. 
The study conforms with the principles outlined in the Declaration of Helsinki and was approved by the hospital medical ethics committee. Every patient received verbal and written information about the study and provided written informed consent. Participation was voluntary and patients were free to withdraw at any time during the study without further explanation or consequences for their treatment.

\section{Study design}

After patients enrolled in the study, echocardiographic and microvascular measurements were performed within 3 days before pacemaker implantation (baseline) and were repeated $60( \pm$ 7) days after CRT. Echocardiographic parameters included LV ejection fraction, $\mathrm{dP} / \mathrm{dt}$ and inter- and intraventricular delays. Endothelial function was assessed by measuring the

105 microvascular perfusion response in the forearm skin upon local heating to $44{ }^{\circ} \mathrm{C}$ and by measuring the response to acetylcholine ( $\mathrm{ACh}$ ) given transcutaneously by iontophoresis. Also, sodium nitroprusside (SNP) was given by iontophoresis to investigate endotheliumindependent reactivity. Within one day after the device had been implanted, atrioventricular and interventricular timings of the pacemaker were optimised by tissue velocity imaging in

110 all patients.

\section{Echocardiography}

Measurements were made according to the criteria published by the American Society of Echocardiography (17). Patients were examined in the left lateral decubitus position using a commercially available system (Vivid 7, GE Healthcare, Horten, Norway). A 3.5-MHz

115 transducer was used to obtain images and was focused at a depth of $16 \mathrm{~cm}$ in the parasternal and apical views (standard long-axis and two- and four-chamber images). 
End-systolic and end-diastolic left ventricular diameters were measured in the parasternal long axis view using the M-mode. Left ventricular ejection fraction was calculated using the modified Simpson's rule from apical four- and two-chamber views. $\mathrm{dP} / \mathrm{dt}$ was measured from

120 the continuous-wave Doppler spectrum of the mitral regurgitation jet.

Intraventricular delays were measured using Tissue Doppler imaging. The sample volume was placed in the basal portions of the septum and the lateral wall. The septal-to-lateral delay in peak velocity was calculated as an indicator of ventricular dyssynchrony. Interventricular time delay was defined as the time difference between the onset of the velocity time integral

125 at the left ventricular outflow tract and the right ventricular outflow tract, using the R-wave on the ECG channel as a reference point.

During follow-up measurements, CRT was optimised prior to the echocardiographic examinations by adjusting the $\mathrm{A}-\mathrm{V}$ and $\mathrm{V}-\mathrm{V}$ interval, such that stroke volume and leftventricular $\mathrm{dP} / \mathrm{dt}$ were maximised. Data were analysed using commercial software (Echopac

130 6.1, General Electric-Vingmed). Echocardiographic measurements were performed by the same experienced sonographer.

\section{Microvascular measurements}

Microvascular function was assessed by iontophoresis of vasoactive drugs and by local heating, both in combination with laser-Doppler flowmetry. Iontophoresis is a method of

135 controlled drug delivery, in which drugs are delivered from an electrode chamber into the skin in a by means of a small, constant electric current. The effects of the drugs on the local microcirculation can be assessed at the same time by a fiberoptic laser-Doppler probe, which is integrated in the electrode chamber $(18 ; 19)$.

A laser-Doppler Perfusion Monitoring unit (PeriFlux 5000, Perimed AB, Järfälla, Sweden)

140 with a laser Doppler probe for iontophoresis (PF481-1, Perimed AB, Järfälla, Sweden) was 
used for the simultaneous delivery of drugs and measurement of local skin perfusion. Furthermore, a thermoregulated laser-Doppler probe (PF457, Perimed AB, Järfälla, Sweden) was used for simultaneous heating of the skin and measurement of perfusion.

Disposable drug delivery electrodes (PF 383, Perimed AB, Järfälla, Sweden) were mounted to the laser Doppler probe to deliver drug solutions to the skin using iontophoresis. A batterypowered iontophoresis controller was used to deliver a constant electric current of $0.02 \mathrm{~mA}$ (PeriIont 382, Perimed AB, Järfälla, Sweden).

Acetylcholine chloride (Miochol®-E $10 \mathrm{mg} / \mathrm{ml}$, Novartis Healthcare, Denmark), and sodium nitroprusside $(25 \mathrm{mg} / \mathrm{ml}$, prepared by hospital pharmacy) were used without further dilution.

150 Drug concentrations were the same throughout the experiments. All drugs were prepared immediately before being used and SNP was kept in the dark.

All experiments were done in a temperature-controlled room $\left(22-23^{\circ} \mathrm{C}\right)$. Patients were seated comfortably in a half upright position during the measurements with one of the forearms rested on an arm support slightly below heart level. After the flexor side of the forearm had been gently cleaned with an ethanol wipe, the iontophoresis probe and accompanying iontophoresis electrode was filled with either ACh or SNP and attached to the skin by double adhesive tape. An indifferent electrode was applied to the wrist and both electrodes were connected to the current controller. Patients rested for 15 minutes before any data were collected. In 1 patient, the response to ACh and SNP was not measured due to technical difficulties.

In previous studies we have optimised our iontophoresis protocols to reduce the vasodilatory effect of the current alone, and to maximise the response to the drugs, with most responses ending as plateaus $(18 ; 20)$. After a current-free baseline period of 1 minute, a constant direct electrical current of $0.02 \mathrm{~mA}$ was applied during 10 minutes, while the perfusion in the area 
165 of the skin under the probe was continuously recorded with a sampling rate of $1 \mathrm{~Hz}$. This procedure was performed for both drugs, and a different area of the skin were used for each drug. ACh was given by anodal iontophoresis, SNP was given by cathodal iontophoresis. Drugs were given in a randomised order.

The thermoregulated probe was attached to the skin by double adhesive tape on a separate area of the same forearm. After a baseline period of 1 minute, the probe was heated to $44{ }^{\circ} \mathrm{C}$. This temperature was reached within a few seconds and was sustained for 20 minutes, while the perfusion in the area of the skin under the probe was measured continuously, also with a sampling rate of $1 \mathrm{~Hz}$.

Each area of measurement on the skin was selected to avoid visible veins and pigmented

175 nevi. The subjects were told to hold their arms still during the experiment.

\section{Data analysis and statistics}

Perfusion responses were calculated as change from baseline, were baseline was defined as the mean perfusion value during 1 minute before starting the local heating or iontophoresis.

The data obtained with the local heating experiments were analysed by calculating the area

180 under the curve from 5 to 20 minutes after the temperature was set to $44{ }^{\circ} \mathrm{C}$, because the perfusion response during the first 5 minutes contains a neurally mediated component. The maximum response to local heating was calculated as the mean response during the last 5 minutes of the measurement.

The data obtained with the iontophoresis experiments were analysed by fitting an $\mathrm{E}_{\max }$ model to the perfusion data as described previously (18). 
The maximum response $\left(\mathrm{E}_{\max }\right)$ and the respective confidence intervals $(95 \% \mathrm{CI})$ were estimated for each response by fitting the model to the perfusion data. Since baseline flow was subtracted, $\mathrm{E}_{\min }$ was constrained to zero.

The significance of the difference in best-fit parameters between baseline and at 2 months

190 CRT was tested using an F-test. Probabilities of less than 0.05 were accepted as significant. Data in the figures are presented as means \pm SEM. For clarity, a limited number of data points are shown in the figures. Data were analysed using GraphPad Prism version 5.00 for Windows (GraphPad Software, San Diego, California, USA). 


\section{Results}

\section{Patient characteristics}

Fifty-five percent of the patients were male. All patients had impaired left ventricular function (LVEF $28 \pm 8$; dP/dt $645 \pm 161$; LV end-systolic diameter $56 \pm 6$; LV end-diastolic diameter $65 \pm 8$ ) and all were in NYHA class 3 when they enrolled in the study. Forty-five percent of the patients did not receive ACE-inhibitors because of contraindications. There were no changes in the use of any of the medications between baseline and 2 months of CRT (McNemar test, $\mathrm{p}>0.24$ ). A detailed summary of the demographic data is given in Table 1. Clinical measures at baseline and follow-up are given in Table 2.

\section{Responses to local heating}

A strong increase in skin perfusion was observed in all patients immediately after the temperature was increased to $44^{\circ} \mathrm{C}$. The perfusion continued to increase gradually during the 20 minutes of local heating. The maximum perfusion and the area under the curve (AUC) were significantly higher 2 months post-CRT compared with the AUC at baseline $(p=0.037$ and $\mathrm{p}=0.047$, respectively). An overview of the results is provided in Table 3 and Figure 1 .

\section{Responses to ACh and SNP}

210 The endothelium-dependent increase in perfusion seen during iontophoresis of ACh was significantly higher 2 months post-CRT compared with baseline ( $\mathrm{E}_{\max }: 31.2 \pm 0.9$ A.U. versus $23.9 \pm 1.7$ A.U, $p=0.005$ ), whereas there was no change in the maximum response to SNP (2 months CRT, $E_{\max }: 21.7 \pm 1.1$ A.U. versus baseline, $21.8 \pm 1.6$ A.U.; $\left.p=0.94\right)$. The results are summarised in Table 3 and Figures 2 (ACh) and 3 (SNP). 


\section{Discussion}

The objective of the current study was to examine whether the endothelium-dependent reactivity of the peripheral microcirculation improves in CHF patients during the first months of resynchronisation therapy. We found that endothelium-dependent vasodilatation, as assessed by local heating and iontophoresis of acetylcholine, is increased in CHF patients within two months of resynchronisation therapy, whereas the total vasodilatory capacity of smooth muscle, measured as the vascular response to sodium nitroprusside, is unchanged.

During recent years, it has been recognised that endothelial dysfunction has a crucial role in the development of symptoms in CHF, such as decreased exercise capacity (2-4; 8). At least

225 part of the reduction in ventricular function is the result of an impaired endotheliumdependent vasodilatory capacity of the coronary vessels. Also, decreased peripheral vasodilatory capacity leads to higher systemic vascular resistance, which further increases cardiac workload and worsens symptoms (21).

One of the most important contributing factors to endothelial dysfunction is the reduction in the availability of NO. Possible mechanisms are the reduction in flow, which leads to less shear stress in conductance and resistance arteries, and the release of increased amounts of reactive oxygen species (ROS), which rapidly inactivate NO. Although CRT does not have a direct effect on peripheral vascular function, it induces favourable changes in peripheral vascular function. A previous study found that CRT acutely improved microcirculatory

235 perfusion, as measured by orthogonal polarisation spectral imaging in the sublingual microvascular bed (14). These acute changes are considered to eventually lead to an improvement in peripheral function, through increased peripheral shear stress, better cardiac loading conditions, and neurohormonal activation. All these may lead to the increase in the production of endothelium-derived NO that we observed in the current study. Another 
240 possible mediator is the effect of CRT on physical activity. At baseline, only one patient was physically active. After 2 months of CRT, 5 patients reported physical activity. Although we were unable to find any difference in the change in microvascular reactivity between patients who became more physically active and patients whoo did not (Student's t-test, $\mathrm{p}>0.12$ ), we can not rule out the possibility of an effect of physical activity, due to the limited statistical 245 power of the study.

The results of the current study also agree with the results from the recent study by Akar et al. (13), who found that responders to CRT could be identified by their endothelial function before implantation, as measured by flow-mediated vasodilatation. They also observed an increase in endothelial function, as assessed by flow-mediated vasodilatation, after 90 days of

250 CRT, although this did not reach statistical significance. Another study showed that after 3 months, CRT improved the post-occlusive hyperaemia response in the forearm (22). Postocclusive reactive hyperaemia is considered to be NO-dependent and the test is often used to assess endothelial function.

There are several methods to quantify endothelium function in the peripheral circulation. The most common is venous occlusion plethysmography after occlusion of the brachial artery or after a challenge with endothelium-dependent and -independent dilators. In the present study, we used local heating and iontophoresis of acetylcholine on the forearm, which are both well established, non-invasive techniques that have been used in a number of previous studies to measure endothelial function. Andersson et al. (2) used the same techniques to compare 260 microvascular reactivity between healthy young adults, healthy elderly adults and elderly adults with heart failure. A clear reduction was found of the vasorelaxant responses in the heart failure group compared to the elderly group without heart failure and compared to the young adults. In a later study (23) it was found that the blood flow responses to local heating were reduced in heart failure patients compared to age- and gender-matched controls. Similar 
265 studies in heart transplantation (7), coronary heart disease (24), diabetes (25) and essential hypertension $(1 ; 26)$ have indicated that impaired microvascular reactivity in the skin, as measured by the techniques used in our study, is related to endothelial dysfunction.

The vasodilatory response seen with local heating is known to be biphasic, with an initial neurally mediated peak and a late plateau which is almost completely dependent on NO

270 production from the endothelium $(27 ; 28)$. Interestingly, although we have often observed the biphasic response to local heating using our protocol in healthy volunteers, we did not observe an initial peak in the blood flow response to local heating in our current study. Whether the absence of an initial peak is the result of an impaired neurogenic response in our patient group remains to be elucidated. The vasodilation induced by exogenous ACh in

275 human skin is mainly mediated by the release of NO from the endothelium through activation of NOS, although part of the response is mediated by prostaglandins, and possibly other factors (29).

This study has a number of limitations. First, the number of included patients is quite small. Also, the number of mechanical responder was high (72-91\% of the patients had improved 280 end-systolic diameter, QRS duration and intraventricular delay). For these reasons, we consider it impossible to relate changes in endothelial function to other known markers that are important in predicting prognosis after CRT. However, even with the limited number of patients, the results indicate that the techniques used in this study are valuable in assessing changes in endothelial function in patients that are treated with CRT, not least since these are established techniques that are noninvasive and relatively easy to perform. We therefore recommend larger longitudinal studies to relate individual improvements in endothelial function to response to therapy.

\section{Acknowledgments}


The authors wish to thank Medtronic NL B.V., Heerlen, The Netherlands, and CoRPS

(Center of Research on Psychology in Somatic Diseases), Department of Medical

Psychology, Tilburg University, the Netherlands for financial support of the study. We want to especially thank professor Susanne Pedersen (CoRPS) for her intellectual input.

\section{Author's contributions}

\begin{tabular}{|c|c|c|c|c|c|c|c|c|}
\hline & $\begin{array}{c}\text { Concept / } \\
\text { Design }\end{array}$ & $\begin{array}{c}\text { Data } \\
\text { collection }\end{array}$ & $\begin{array}{c}\text { Data } \\
\text { Analysis / } \\
\text { interpreta } \\
\text { tion }\end{array}$ & $\begin{array}{c}\text { Drafting } \\
\text { article }\end{array}$ & $\begin{array}{c}\text { Critical } \\
\text { revision }\end{array}$ & Approval & Statistics & Funding \\
\hline ET & $\mathrm{x}$ & $\mathrm{x}$ & $\mathrm{x}$ & $\mathrm{x}$ & $\mathrm{x}$ & $\mathrm{x}$ & $\mathrm{x}$ & \\
\hline $\mathrm{AS}$ & $\mathrm{x}$ & $\mathrm{x}$ & $\mathrm{x}$ & $\mathrm{x}$ & $\mathrm{x}$ & $\mathrm{x}$ & $\mathrm{x}$ & \\
\hline $\mathrm{JW}$ & $\mathrm{x}$ & & $\mathrm{x}$ & $\mathrm{x}$ & $\mathrm{x}$ & $\mathrm{x}$ & & $\mathrm{x}$ \\
\hline $\mathrm{HB}$ & & $\mathrm{x}$ & & & $\mathrm{x}$ & $\mathrm{x}$ & & \\
\hline $\mathrm{EC}$ & & $\mathrm{x}$ & & & $\mathrm{x}$ & $\mathrm{x}$ & & \\
\hline $\mathrm{CL}$ & & $\mathrm{x}$ & & & $\mathrm{x}$ & $\mathrm{x}$ & & \\
\hline JC & & & & & $\mathrm{x}$ & $\mathrm{x}$ & & $\mathrm{x}$ \\
\hline
\end{tabular}




\section{Tables}

295 Table 1. Characteristics of the patients included in the study.

Patient Characteristics $(\mathrm{N}=11)$

\section{Demographics}

sex (male)

$55 \%$

Medication

$\begin{array}{ll}\text { ACE } & 55 \% \\ \text { digoxin } & 9 \% \\ \text { beta blockers } & 91 \% \\ \text { aldosterone antagonists } & 36 \% \\ \text { statines } & 27 \% \\ \text { aspirin } & 64 \% \\ \text { loop diuretics } & 91 \%\end{array}$

Comorbidities

$\begin{array}{ll}\text { hypertension } & 64 \% \\ \text { lipid disorders } & 64 \% \\ \text { diabetes mellitus type II } & 27 \% \\ \text { COPD } & 9 \%\end{array}$

Cardiac History

Myocardial infarction $\quad 50 \%$

Arrhythmia $\quad 17 \%$

PCI $33 \%$

CABG $25 \%$ 
Table 2. Clinical and echocardiographic measures at baseline and after 2 months of CRT. ${ }^{*} p<0.05$; ${ }^{* *} p<0.01$.

\begin{tabular}{llllll} 
& Baseline & \multicolumn{3}{l}{ months CRT } \\
\hline Clinical measures & mean & SD & mean & SD & p-value \\
\hline Age (years) & 70.5 & $(7.4)$ & & & \\
NYHA class & 3 & $(0)$ & 2.9 & $(0.3)$ & 0.34 \\
Systolic blood pressure (mmHg) & 133 & $(28)$ & 125 & $(22)$ & 0.37 \\
Diastolic blood pressure (mmHg) & 76 & $(8.0)$ & 75 & $(8.1)$ & 0.91 \\
Left ventricular ejection fraction (\%) & 28 & $(7.6)$ & 32 & $(8.3)$ & 0.68 \\
dP/dt (mmHg) & 645 & $(161)$ & 886 & $(280)$ & 0.07 \\
LV end-systolic diameter (mm) & 56 & $(6.1)$ & 50 & $(9.2)$ & $0.04 *$ \\
LV end-diastolic diameter (mm) & 65 & $(8.4)$ & 61 & $(9.9)$ & $0.012^{*}$ \\
LV intraventricular delay (ms) & 49 & $(30)$ & 24 & $(18)$ & $0.005^{* *}$ \\
Heart rate (min-1) & 70 & $(17)$ & 69 & $(8.3)$ & 0.76 \\
QRS duration (ms) & 154 & $(32)$ & 112 & $(21)$ & $0.0012^{* *}$ \\
\hline
\end{tabular}


Table 3. Skin blood flow responses to local heating and iontophoresis of acetylcholine 300 (endothelium-dependent) and nitroprusside (endothelium-independent).

Local heating

\begin{tabular}{llllll}
\hline & Baseline & \multicolumn{5}{c}{2 months CRT } \\
\hline & Mean & SD & Mean & SD & p-value \\
Baseline perfusion & 7.9 & $(3.5)$ & 9.1 & $(4.6)$ & 0.2 \\
Maximum response & 97 & $(42)$ & 137 & $(53)$ & $0.037^{*}$ \\
AUC & 1466 & $(991)$ & 2205 & $(770)$ & $0.047^{*}$
\end{tabular}

Acetylcholine iontophoresis

\begin{tabular}{llllll}
\multicolumn{2}{c}{ Baseline } & \multicolumn{5}{c}{2 months CRT } \\
\hline & Mean & SD & Mean & SD & p-value \\
Baseline perfusion & 3.1 & $(1.3)$ & 3.3 & $(2.3)$ & 0.85 \\
Emax & 23.9 & $(1.7)$ & 31.2 & $(0.9)$ & $0.005^{* *}$
\end{tabular}

Sodium Nitroprusside iontophoresis

\begin{tabular}{llllll}
\hline & Baseline & \multicolumn{3}{c}{2 months CRT } \\
\hline & Mean & SD & Mean & SD & p-value \\
Baseline perfusion & 2.9 & $(0.8)$ & 2.5 & $(1.3)$ & 0.84 \\
Emax & 21.8 & $(1.6)$ & 21.7 & $(1.1)$ & 0.94
\end{tabular}




\section{Figures}

Figure 1. Skin hyperemic blood flow response to local heating to $44^{\circ} \mathrm{C}$ before and after 2 months of CRT. Maximum vasodilatation and area under the curve were significantly increased after 2 months of CRT.

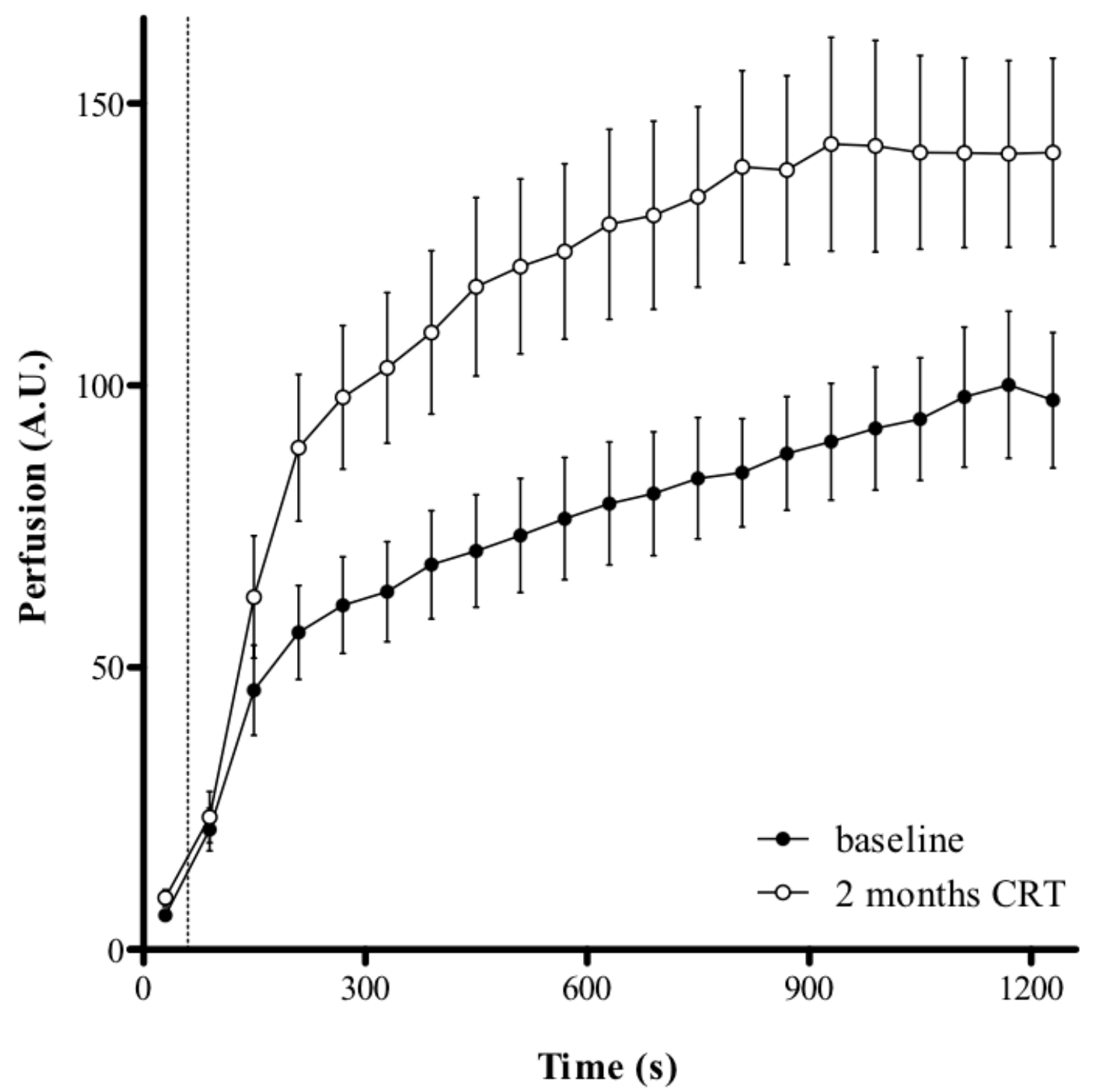


Figure 2. Endothelium-dependent blood flow response to acetylcholine delivered by iontophoresis.

The maximum vasodilatory response was significantly increased after 2 months of CRT.

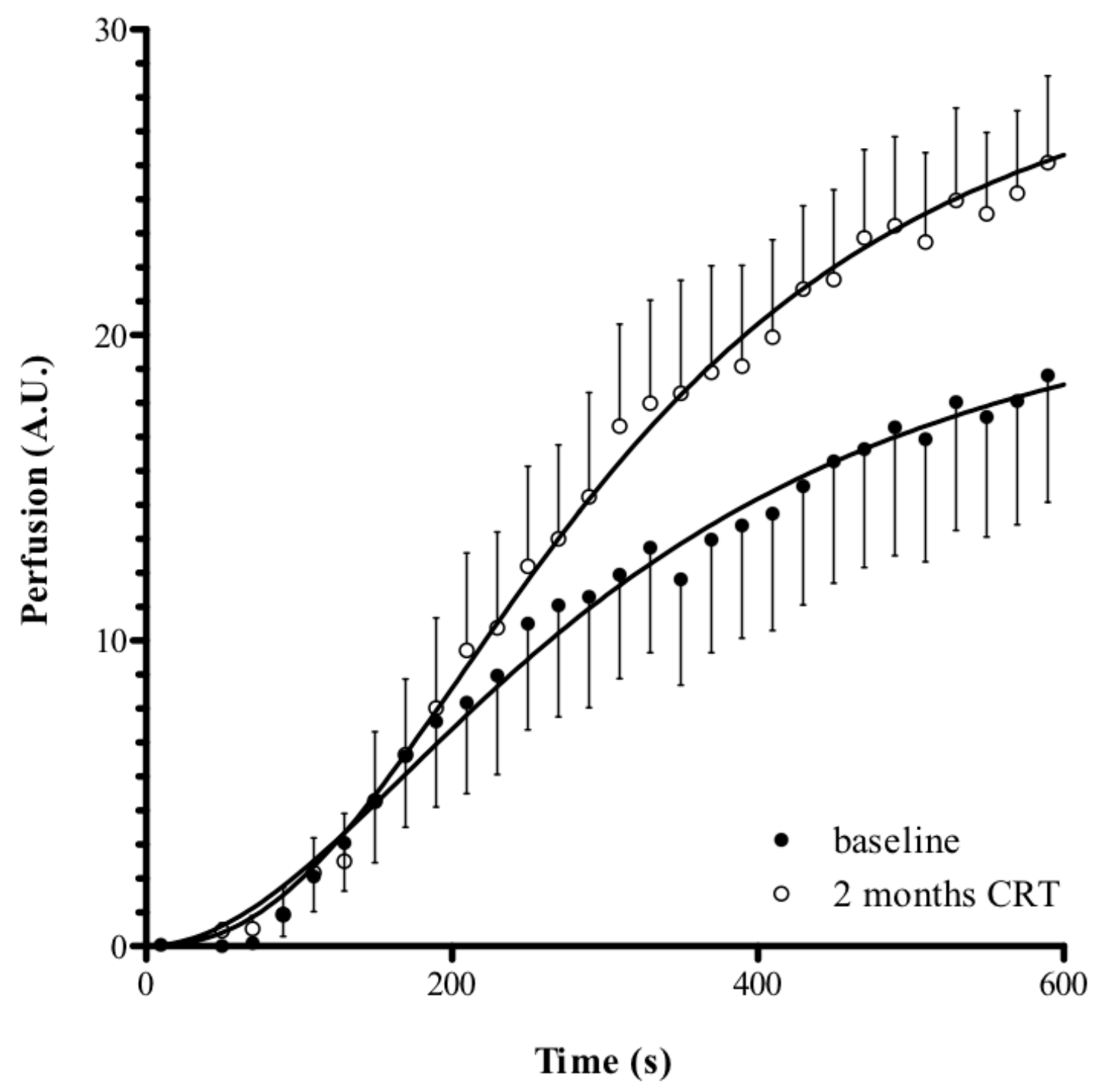


Figure 3. Total vasodilatory capacity as measured by the skin blood flow response to sodium nitroprusside delivered by iontophoresis. There was no difference between responses at baseline and after 2 months of CRT.

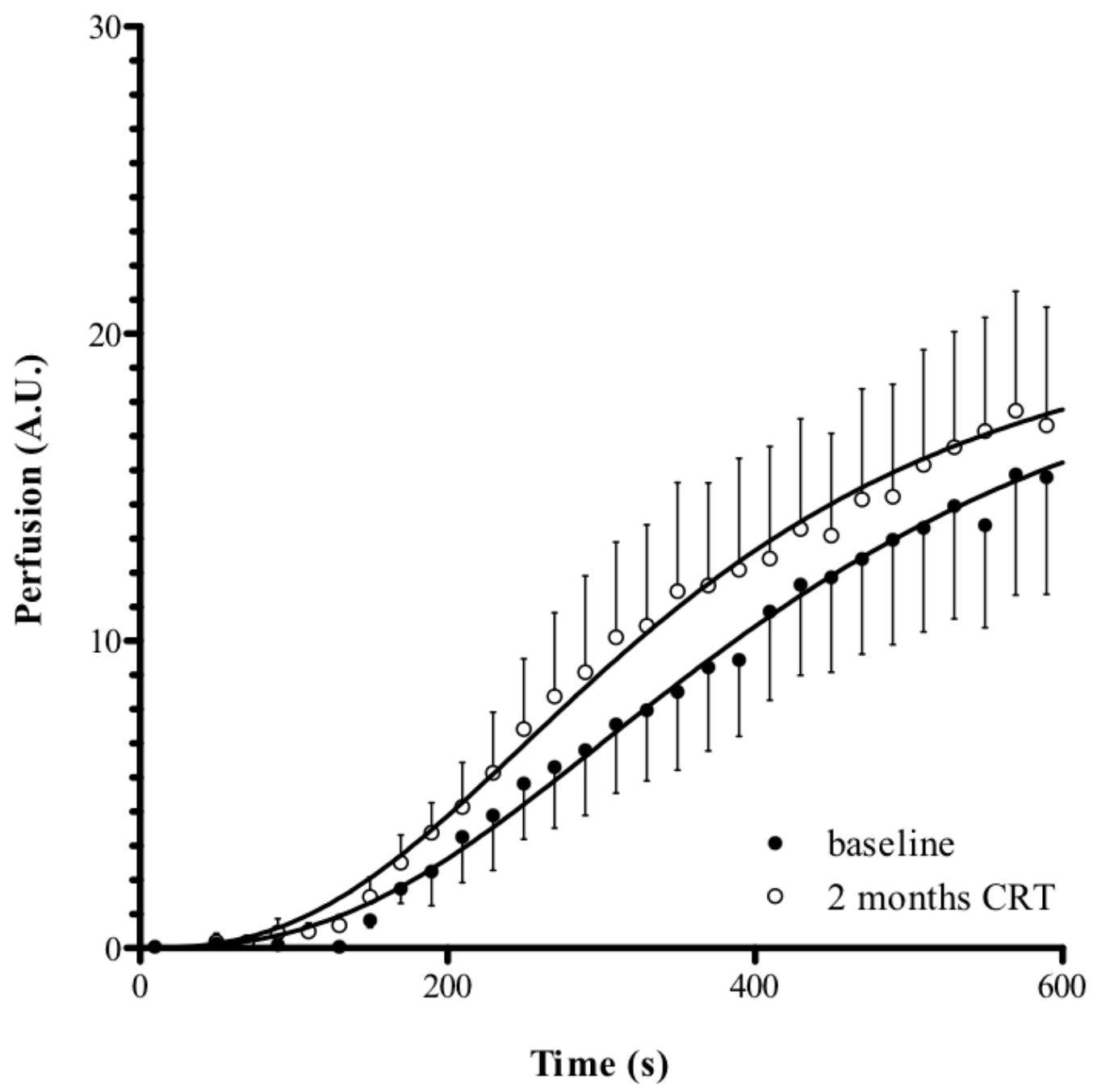

\section{References}

315 1. Cupisti A, Rossi M, Placidi S, Fabbri A, Morelli E, Vagheggini G, Meola M, et al. 2000.

Responses of the skin microcirculation to acetylcholine in patients with essential hypertension and in normotensive patients with chronic renal failure. Nephron. 85, 114-119.

2. Andersson SE, Edvinsson ML, Edvinsson L. 2003. Cutaneous vascular reactivity is reduced in 
aging and in heart failure: association with inflammation. Clin Sci (Lond). 105, 699-707.

320 3. Drexler H, Hornig B. 1999. Endothelial dysfunction in human disease. J Mol Cell Cardiol. 31, $51-60$.

4. Fischer D, Rossa S, Landmesser U, Spiekermann S, Engberding N, Hornig B, Drexler H. 2005. Endothelial dysfunction in patients with chronic heart failure is independently associated with increased incidence of hospitalization, cardiac transplantation, or death. Eur Heart J. 26, 6569.

5. Heitzer T, Baldus S, von Kodolitsch Y, Rudolph V, Meinertz T. 2005. Systemic endothelial dysfunction as an early predictor of adverse outcome in heart failure. Arterioscler Thromb Vasc Biol. 25, 1174-1179.

6. Heitzer T, Schlinzig T, Krohn K, Meinertz T, Munzel T. 2001. Endothelial dysfunction, oxidative stress, and risk of cardiovascular events in patients with coronary artery disease. Circulation. 104, 2673-2678.

7. Andreassen AK, Gullestad L, Holm T, Simonsen S, Kvernebo K. 1998. Endotheliumdependent vasodilation of the skin microcirculation in heart transplant recipients. Clin Transplant. 12, 324-332.

335 8. Hognestad A, Holm T, Simonsen S, Kjekshus J, Andreassen AK. 2005. Serial measurements of peripheral vascular reactivity and exercise capacity in congestive heart failure and after heart transplantation. J Card Fail. 11, 447-454.

9. Roig E, Cuppoletti A, Masotti M, Kianco R, Vallejos I, Sitges M, Ortiz J, et al. 2009. Assessment of peripheral endothelial-dependent vasodilatation within the first year after heart transplantation. J Heart Lung Transplant. 28, 299-304.

10. Cleland JG, Calvert MJ, Verboven Y, Freemantle N. 2009. Effects of cardiac resynchronization therapy on long-term quality of life: an analysis from the CArdiac Resynchronisation-Heart Failure (CARE-HF) study. Am Heart J. 157, 457-466.

11. Cleland JG, Daubert JC, Erdmann E, Freemantle N, Gras D, Kappenberger L, Tavazzi L. 2005. The effect of cardiac resynchronization on morbidity and mortality in heart failure. $N$ Engl J Med. 352, 1539-1549. 
12. Freemantle N, Tharmanathan P, Calvert MJ, Abraham WT, Ghosh J, Cleland JG. 2006. Cardiac resynchronisation for patients with heart failure due to left ventricular systolic dysfunction -a systematic review and meta-analysis. Eur J Heart Fail. 8, 433-440.

350 13. Akar JG, Al-Chekakie MO, Fugate T, Moran L, Froloshki B, Varma N, Santucci P, et al. 2008. Endothelial dysfunction in heart failure identifies responders to cardiac resynchronization therapy. Heart Rhythm. 5, 1229-1235.

14. Erol-Yilmaz A, Atasever B, Mathura K, Lindeboom J, Wilde A, Ince C, Tukkie R. 2007. Cardiac resynchronization improves microcirculation. J Card Fail. 13, 95-99.

15. Krum H. 2005. The Task Force for the diagnosis and treatment of chronic heart failure of the European Society of Cardiology. Guidelines for the diagnosis and treatment of chronic heart failure: full text (update 2005). Eur Heart J. 26, 2472; author reply 2473-2474.

16. Hunt SA, Abraham WT, Chin MH, Feldman AM, Francis GS, Ganiats TG, Jessup M, et al. 2005. ACC/AHA 2005 Guideline Update for the Diagnosis and Management of Chronic Heart Failure in the Adult: a report of the American College of Cardiology/American Heart Association Task Force on Practice Guidelines (Writing Committee to Update the 2001 Guidelines for the Evaluation and Management of Heart Failure): developed in collaboration with the American College of Chest Physicians and the International Society for Heart and Lung Transplantation: endorsed by the Heart Rhythm Society. Circulation. 112, e154-235.

365 17. Schiller NB, Shah PM, Crawford M, DeMaria A, Devereux R, Feigenbaum H, Gutgesell H, et al. 1989. Recommendations for quantitation of the left ventricle by two-dimensional echocardiography. American Society of Echocardiography Committee on Standards, Subcommittee on Quantitation of Two-Dimensional Echocardiograms. J Am Soc Echocardiogr. 2, 358-367.

370 18. Henricson J, Tesselaar E, Persson K, Nilsson G, Sjoberg F. 2007. Assessment of microvascular function by study of the dose-response effects of iontophoretically applied drugs (acetylcholine and sodium nitroprusside)--methods and comparison with in vitro studies. Microvasc Res. 73, 143-149.

19. Tesselaar E, Sjoberg F. 2010. Transdermal iontophoresis as an in-vivo technique for studying 
microvascular physiology. Microvasc Res.

20. Droog EJ, Henricson J, Nilsson GE, Sjoberg F. 2004. A protocol for iontophoresis of acetylcholine and sodium nitroprusside that minimises nonspecific vasodilatory effects. Microvasc Res. 67, 197-202.

21. Bauersachs J, Schafer A. 2004. Endothelial dysfunction in heart failure: mechanisms and therapeutic approaches. Curr Vasc Pharmacol. 2, 115-124.

22. Flevari P, Theodorakis G, Paraskevaidis I, Kolokathis F, Kostopoulou A, Leftheriotis D, Kroupis C, et al. 2006. Coronary and peripheral blood flow changes following biventricular pacing and their relation to heart failure improvement. Europace. 8, 44-50.

23. Andersson SE, Edvinsson ML, Alving K, Edvinsson L. 2005. Vasodilator effect of endothelin in cutaneous microcirculation of heart failure patients. Basic Clin Pharmacol Toxicol. 97, 8085.

24. RG IJ, de Jongh RT, Beijk MA, van Weissenbruch MM, Delemarre-van de Waal HA, Serne EH, Stehouwer CD. 2003. Individuals at increased coronary heart disease risk are characterized by an impaired microvascular function in skin. Eur J Clin Invest. 33, 536-542.

390 25. Morris SJ, Shore AC, Tooke JE. 1995. Responses of the skin microcirculation to acetylcholine and sodium nitroprusside in patients with NIDDM. Diabetologia. 38, 1337-1344.

26. Farkas K, Kolossvary E, Jarai Z, Nemcsik J, Farsang C. 2004. Non-invasive assessment of microvascular endothelial function by laser Doppler flowmetry in patients with essential hypertension. Atherosclerosis. 173, 97-102.

395 27. Kellogg DL, Jr. 2006. In vivo mechanisms of cutaneous vasodilation and vasoconstriction in humans during thermoregulatory challenges. J Appl Physiol. 100, 1709-1718.

28. Kellogg DL, Jr., Zhao JL, Wu Y. 2009. Roles of nitric oxide synthase isoforms in cutaneous vasodilation induced by local warming of the skin and whole body heat stress in humans. $J$ Appl Physiol. 107, 1438-1444.

400 29. Kellogg DL, Jr., Zhao JL, Coey U, Green JV. 2005. Acetylcholine-induced vasodilation is mediated by nitric oxide and prostaglandins in human skin. J Appl Physiol. 98, 629-632. 


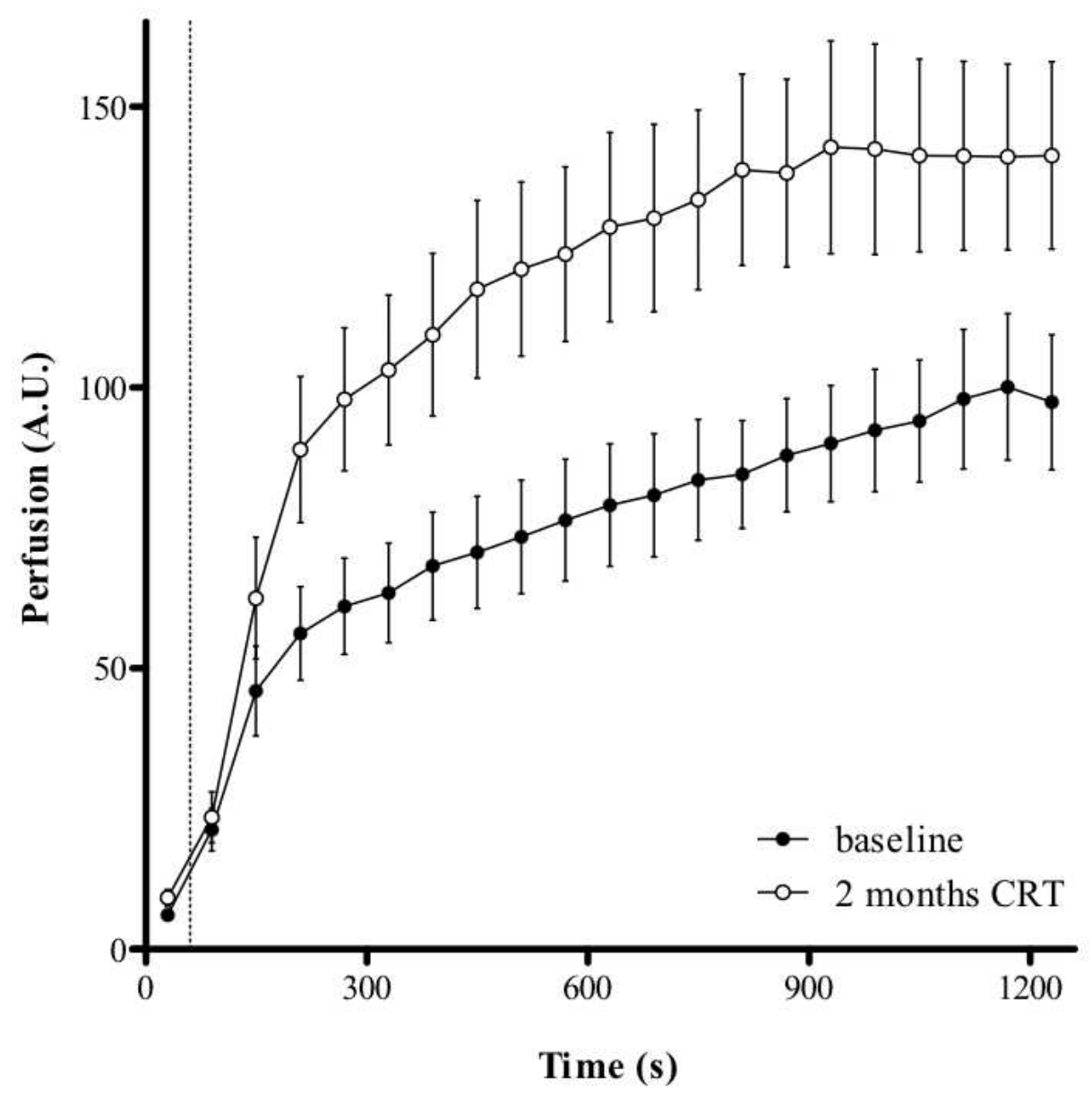

Figure 1. Skin hyperemic blood flow response to local heating to $440 \mathrm{C}$ before and after 2 months of CRT. Maximum vasodilatation and area under the curve were significantly increased after 2 months of CRT.

$127 \times 130 \mathrm{~mm}(150 \times 150 \mathrm{DPI})$ 


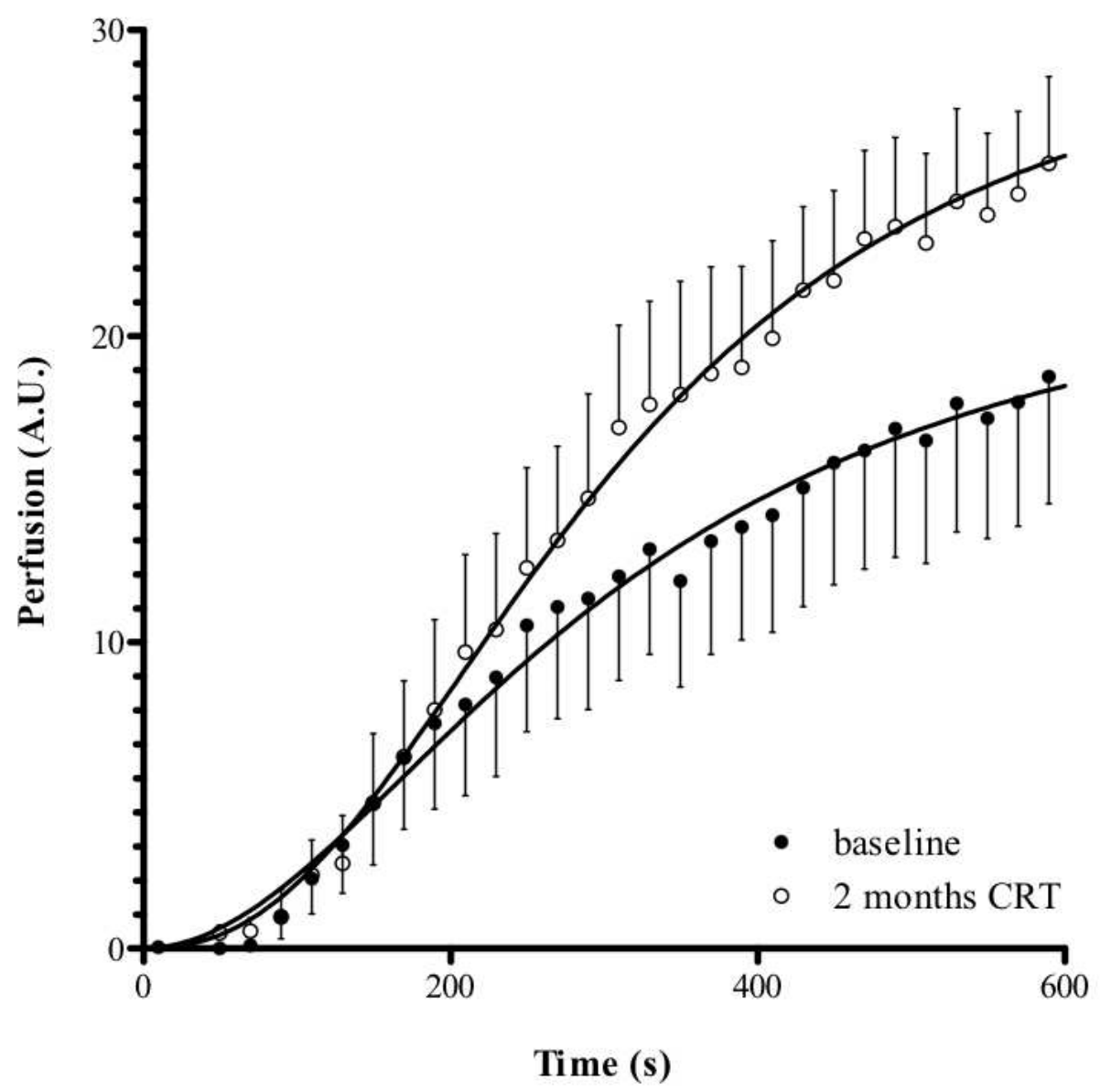

Figure 2. Endothelium-dependent blood flow response to acetylcholine delivered by iontophoresis. The maximum vasodilatory response was significantly increased after 2 months of CRT. $131 \times 133 \mathrm{~mm}(150 \times 150 \mathrm{DPI})$ 


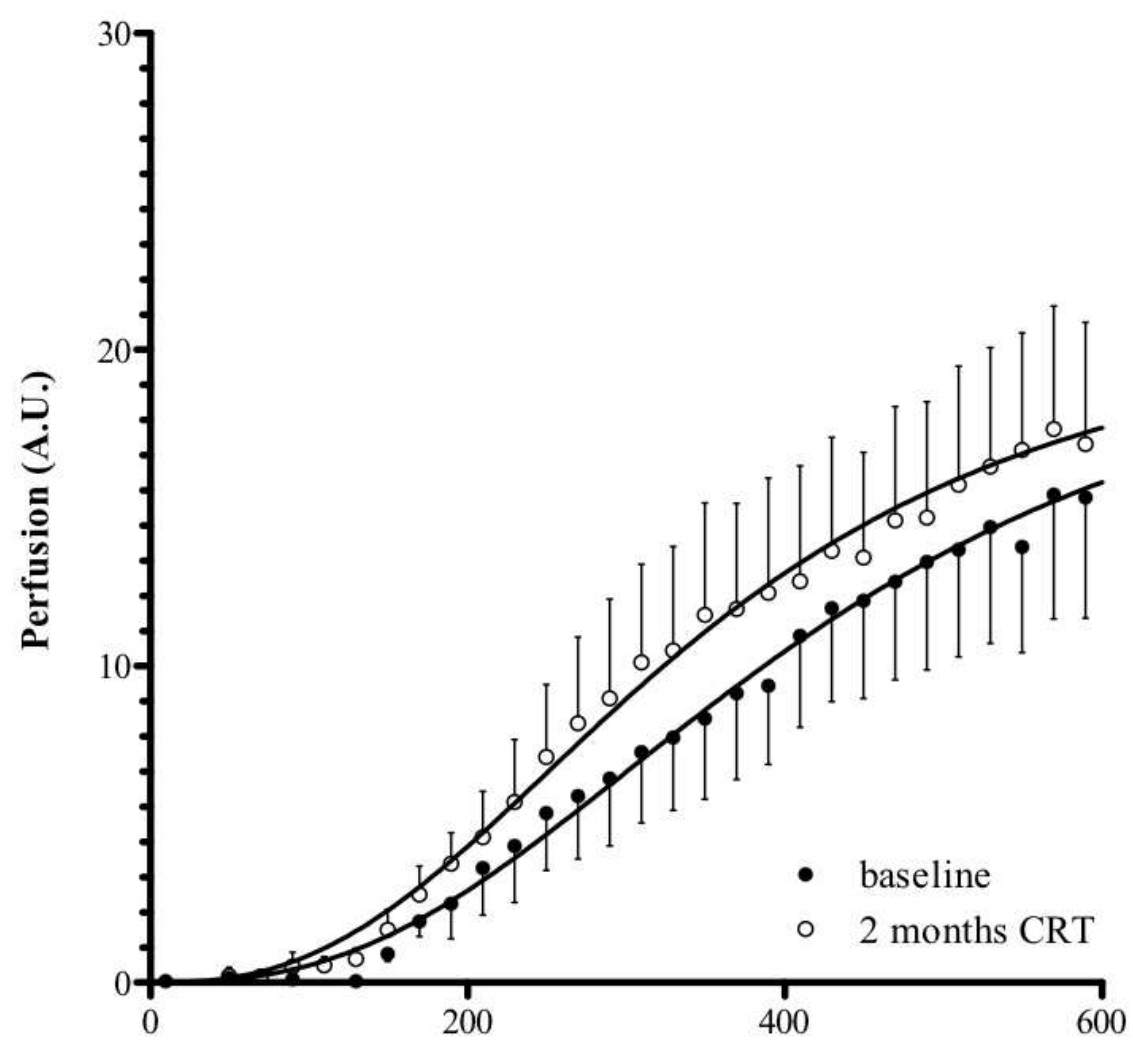

Time (s)

Figure 3. Total vasodilatory capacity as measured by the skin blood flow response to sodium nitroprusside delivered by iontophoresis. There was no difference between responses at baseline and after 2 months of CRT. $139 \times 129 \mathrm{~mm}(150 \times 150 \mathrm{DPI})$ 